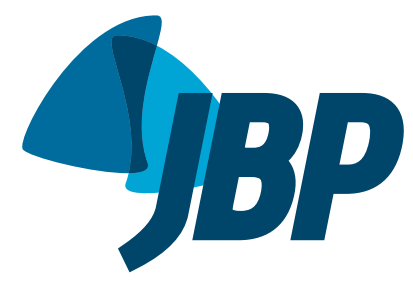

\title{
Treatment compliance of patients with paracoccidioidomycosis in Central-West Brazil
}

\author{
Ursulla Vilella Andrade ${ }^{1, a}$, Sandra Maria do Valle Leone de Oliveira ${ }^{1, b}$, \\ Marilene Rodrigues Chang ${ }^{1, c}$, Edy Firmina Pereira, ${ }^{1, d}$, \\ Ana Paula da Costa Marques, ${ }^{1, e}$, Lidia Raquel de Carvalho, ${ }^{2, f}$, \\ Rinaldo Poncio Mendes ${ }^{2, s}$, Anamaria Mello Miranda Paniago ${ }^{1, h}$
}

1. Universidade Federal de Mato Grosso do Sul, Campo Grande, MS, Brazil.

2. Universidade Estadual de São Paulo, Botucatu, SP, Brazil.

a. (iD http://orcid.org/0000-0002-6932-1692

b. (iD http://orcid.org/0000-0002-8960-6716

c. (iD http://orcid.org/0000-0003-3402-4740

d. (iD http://orcid.org/0000-0003-3011-6947

e. (D) http://orcid.org/0000-0003-4012-0720

f. (D) http://orcid.org/0000-0003-0575-2263

g. (iD) http://orcid.org/0000-0002-0661-5917

h. (D) http://orcid.org/0000-0002-8925-7712

Submitted: 30 May 2018

Accepted: 23 December 2018

Study carried out in Universidade Federal de Mato Grosso do Sul, Campo Grande, MS, Brazil.

\begin{abstract}
Objective: To evaluate the treatment compliance of patients with paracoccidioidomycosis Methods: We studied 188 patients with paracoccidioidomycosis admitted to a tertiary referral hospital in the Central-West Region of Brazil from 2000 to 2010, to assess their compliance to treatment. In order to be considered compliant, patients needed to present two established criteria: (1) receive medicines from the pharmacy, and (2) achieve a selfreported utilization of at least $80 \%$ of the dispensed antifungal compounds prescribed since their previous appointment. Results: Most patients were male (95.7\%), had the chronic form of the disease $(94.2 \%)$, and were treated with cotrimoxazole $(86.2 \%)$. Only $44.6 \%$ of patients were treatment compliant. The highest loss to follow-up was observed in the first 4 months of treatment $(p<0.02)$. Treatment compliance was higher for patients with than for those without pulmonary involvement $(\mathrm{OR}: 2.986 ; 95 \% \mathrm{Cl}$ 1.351-6.599), and higher for patients with than without tuberculosis as co-morbidity (OR: 2.763; 95\% Cl 1.004-7.604). Conclusions: Compliance to paracoccidioidomycosis treatment was low, and the period with the highest loss to follow-up corresponds to the first four months. Pulmonary paracoccidioidal involvement or tuberculosis comorbidity predicts a higher compliance to paracoccidioidomycosis therapy.

Keywords: Paracoccidioidomycosis; Treatment adherence and compliance; loss to follow-up; mycoses
\end{abstract}

\section{INTRODUCTION}

Paracoccidioidomycosis (PCM) is a systemic mycosis caused by Paracoccidioides brasiliensis and Paracoccidioides lutzii that is endemic in Latin America. ${ }^{(1)}$ Cases diagnosed in other countries are usually imported ones involving people who moved from Latin America. ${ }^{(1,2)}$ In Brazil, the mortality rate for PCM is 1.45 per 1 million inhabitants, making it the eighth most common cause of mortality among chronic recurrent infectious and parasitic diseases. ${ }^{(3)}$ The fatality rate is between 5 and $27 \%$. $^{(3,4)}$ The main therapeutic challenges of PCM are its long duration, the high frequency of relapses and sequelae, and comorbidities. The most frequently observed comorbidities are endemic diseases such as tuberculosis, intestinal helminthiases, and cigarette smoking. ${ }^{(5,6)}$ PCM treatment continues until an apparent cure is reached; the term "apparent cure" is preferred to that of "cure" because it is impossible to confirm the eradication of the fungus from the affected individual. ${ }^{(7)}$ Treatment duration depends on host immunity, virulence of the isolate, Paracoccidioides sp inoculum size, and the antifungal compound used. The duration of the treatment is usually maintained until the recovery of cell-mediated immunity ${ }^{(8,9)}$ to avoid reactivation of the fungal cells, which can persist as latent foci.
Compliance, i.e. the act of taking medications as prescribed, is a highly complex clinical behavior, and its evaluation remains problematic. ${ }^{(10)}$ Non-compliance to chronic disease therapy is a problem faced by many health services and is the main obstacle to cure. ${ }^{(11)}$ It may result in disease progression and, when caused by an infectious agent, resistant microorganisms. Long-term treatment of PCM can lead to a non-compliance. . $^{(5,12-14)}$

The purpose of this study was to assess the factors associated with treatment compliance for patients with PCM, aiming to design interventions to improve the care and quality of life for these patients.

\section{METHODS}

This study was conducted at the Hospital Dia Professora Esterina Corsini at the Universidade Federal de Mato Grosso do Sul, which is a reference center for PCM. All patients with active PCM admitted between January 2000 and December 2010 were invited to participate in the present investigation. Only confirmed cases, characterized by the presence of clinical manifestations compatible with PCM and the identification of typical Paracoccidioides spp. yeast forms using direct mycological

Correspondence to:

Anamaria Mello Miranda Paniago. School of Medicina, Universidade Federal de Mato Grosso do Sul, Rua Fillinto Muller, 355, Zip code, Campo Grande, MS, Brazil Tel.: 55 99912-0164. E-mail: anapaniago@yahoo.com.br

Financial support: Fundação de Apoio ao Desenvolvimento do Ensino, Ciência e Tecnologia do Estado de Mato Grosso do Sul/ Brazilian National Council for Scientific and Technological Development (Fundect-MS/CNPq)

Conflicts of interest: The authors declare that they have no conflict of interest. 
or histopathological examination, were included in this study. Patients who died at the beginning of their treatment were excluded. This study used data collected prospectively by a standardized form with demographic, epidemiological, and clinical data. The same physician supervised the patients throughout the study period.

The antifungal compounds used for initial treatment were selected considering severity of disease, possibility of gastrointestinal absorption of the drug, and the presence of associated diseases. For some cases of severe forms, the dose of conventional amphotericin B 0.5 to $0.7 \mathrm{mg} / \mathrm{kg} /$ day was indicated. Intravenous trimethoprim-sulfamethoxazole combination (cotrimoxazole) was prescribed at a dose of $800 \mathrm{mg} / 160 \mathrm{mg}$ every 8 hours for at initial treatment of some severe cases. For most of the cases, cotrimoxazole was administered at a dose of $1,200 \mathrm{mg} / 240 \mathrm{mg}$ every 12 hours or itraconazole $200 \mathrm{mg}$ once at day was indicated. For complementary treatment, cotrimoxazole was prescribed at a dose of $800 \mathrm{mg} / 160 \mathrm{mg}$ every 12 hours, while itraconazole was prescribed at the same dose as during initial treatment.

The follow-up regimen included re-evaluation after 1 month of treatment, then every 2 months thereafter until clinical cure was reached. Clinical cure was defined as the disappearance of the previously observed symptoms and normalization of the erythrocyte sedimentation rate. Patients were then evaluated every 2 to 3 months until serological cure by immunodiffusion. ${ }^{(7)}$ Treatment with itraconazole was maintained for at least 1 year, whereas the cotrimoxazole was continued for at least 2 years. After this period, the drug was suspended if the patient had reached and maintained serological cure for 6 months. Patients whose initial serology was unreactive or not performed used the time for treatment above described. All the antifungal compounds were provided to the patients at no cost.

Treatment compliance was defined by the presence of two conditions: (1) appointment compliance of, at least $80 \%$ of appointments during the follow-up period; and (2) medication compliance, having pharmacy confirmed drug dispensing and the patient reported the administration of at least $80 \%$ of the antifungal doses prescribed since their previous appointment.

Cigarette smoking, alcoholism and tuberculosis were included in the analysis as co-morbidities. We defined smokers as those who reported smoking one or more cigarettes per day, while alcohol users were those who reported regularly drinking alcohol, and tuberculosis was defined by the identification of acid-fast bacilli in histopathological examination, sputum smears, or culture of clinical specimens.

Statistical analysis was performed using Epi Info $^{\mathrm{TM}} 7$ (Centers for Disease Control and Prevention, Atlanta, GA, USA). Categorical variables were expressed as percentages and were compared using the Chi-squared test, or the Fisher's exact test. The Cochran Q test was used to compare percentages in dependent populations.
Odds ratios (OR) and 95\% confidence intervals (95\%CI) were used to assess the association of the variables with compliance. Confounding effects were minimized by performing binary logistic regression adjusting for potential confounders identified in the analysis. These potential confounders are variables that were found to have $p \leq 0.20$. The level of significance used in the analysis was 0.05 .

This study was approved by the Ethics Committee of the Universidade Federal de Mato Grosso do Sul (CAE 05200812.0.0000.0021).

\section{RESULTS}

A total of 188 patients were initially enrolled in the study, with a mean of 17 cases per year. As 4 patients $(2.1 \%)$ died at the beginning of the initial therapy and were excluded from the study, 184 cases were analyzed (Figure 1). The patients' ages ranged from 4 to 94 years (median: 48 years). The male-to-female ratio was $22.5: 1.0$. In all, $82.4 \%$ of patients were rural workers, $93.1 \%$ were cigarette smokers, and $81.9 \%$ had alcoholism. The median time between onset of symptoms and diagnosis was 5 months, ranging from 1 to 120 months. Sequelae characterized by fibrotic scars occurred in $77(41 \%)$ patients, with predominance in the lungs, where it was detected in 66 (35.8\%) patients, by thorax radiography or computed tomography (CT scan). Other sites with fibrotic scars were observed in adrenal glands ( 8 patients; $4.3 \%$ ) by CT scan; in the larynx ( 6 patients; $3.3 \%$ ) by laryngoscopy, in the mouth (4 patients; $2.2 \%$ ) and skin (3 patients; $1.6 \%$ ) through physical examination.

Eighty-six patients completed the treatment, 45 (52.3\%) of them had serological cure; at admission, $21(24.4 \%)$ patients showed no reagent serology at admission, and in 20 (23.2\%) the serological evaluation was not carried out.

This study shows that only $82(44.6 \%)$ patients were treatment compliant. The main loss to follow-up was observed in the first 4 months of treatment, which was showed by the decrease in the prevalence of the appointments. This prevalence was stable until the $12^{\text {th }}$ month of follow-up, when a new decrease could be observed (Figure 2).

Demographic and epidemiological characteristics were not associated with treatment compliance; however pulmonary paracoccidioidal involvement and PCM tuberculosis co-infection were associated with higher treatment compliance, 2.99 and 2.76 times more, respectively (Tables 1 and 2 ).

\section{DISCUSSION}

The profile of patients with PCM included in this study was in line with the characteristics most frequently reported in the literature - middle-aged males, whose professional activity was associated with intense contact with soil, as well as increased prevalence of the chronic form of the disease. ${ }^{(12-14)}$ Poor treatment 


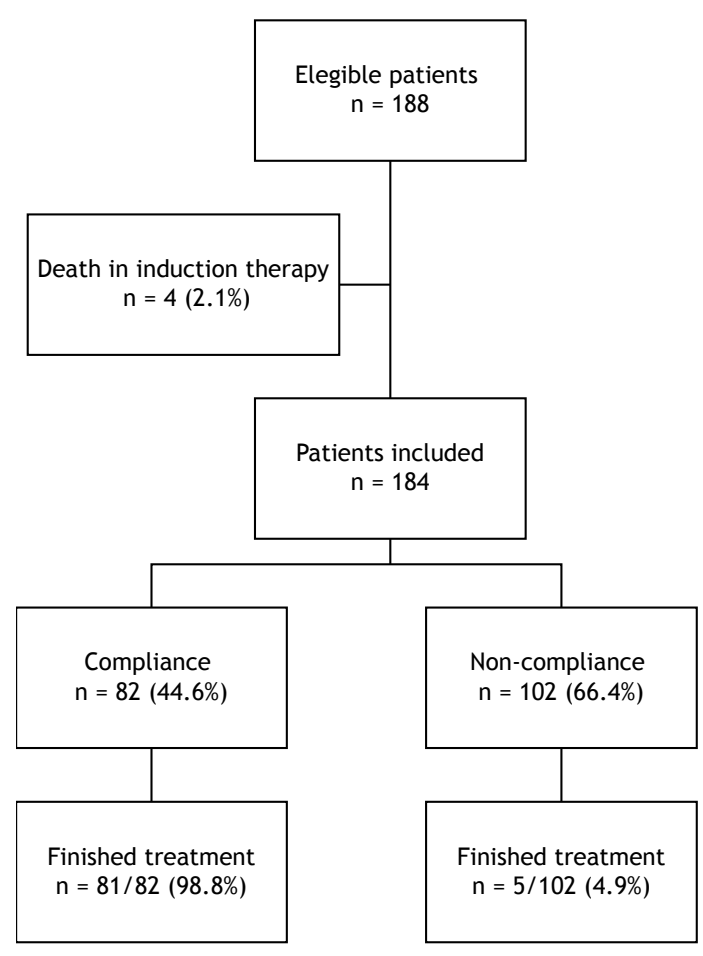

Figure 1. Flowchart of treatment compliance of 188 patients with paracoccidioidomycosis.

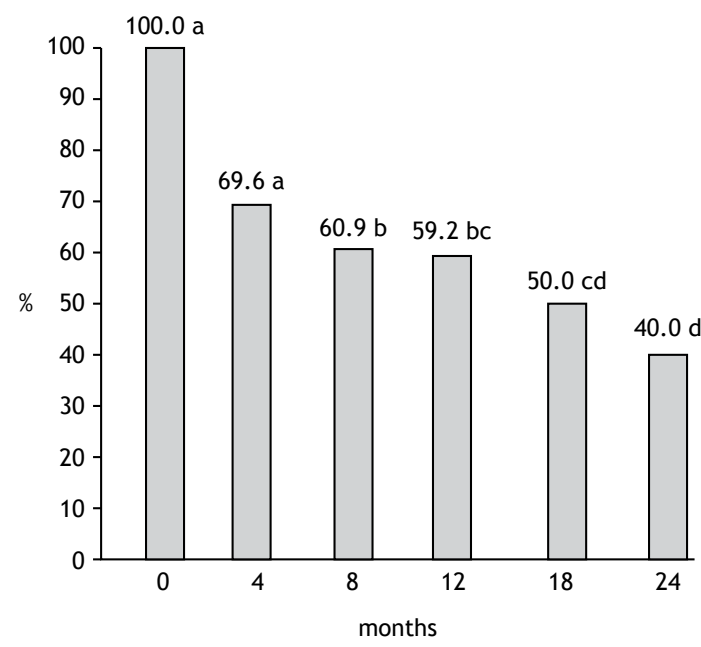

Figure 2. Follow-up of clinical appointments of 184 patients with paracoccidioidomycosis. Cochran $\mathrm{Q}$ test. Frequencies followed by the same letters do not differ ( $p>0.05)$; frequencies followed by different letters indicate statistically significant differences ( $p \leq 0.05)$.

compliance was also observed in our study. In developing countries, treatment compliance for chronic conditions often reaches only $20 \%$, leading to negative health statistics and very high costs to society, government, and families of patients. ${ }^{(11)}$

In contrast, a Brazilian study carried out in 2008 reported a global attendance of scheduled follow-ups, and treatment compliance of $88.2 \%$. ${ }^{(10)}$ In that study, the average individual clinic attendance compliance (ICAC) of 132 patients, with at least 10 routine appointments was $90.3 \%$, with $85.6 \%$ of patients attending at least $80 \%$ of these clinical evaluations. Mean ( \pm standard deviation) ICAC did not vary with clinical presentation: $90.8 \pm 11.9 \%$ for patients with the chronic form of the disease and $88.2 \pm 9.9 \%$ for those with the acute/ subacute form $(p>0.05)$. It should be noted that this service has different characteristics from the other care centers in the country, with a greater emphasis on patient follow-up.

In this same study, the antifungal compliance (appropriate sulfonamide serum levels) of 95 patients treated with trimethoprim-sulfamethoxazole combination therapy was $42.1 \%$, showing that patient self-reporting, in order to assess medication-taking, tends to overestimate compliance. ${ }^{(10)}$ Blood level monitoring of sulfonamides in $\mathrm{PCM}^{(15)}$ and of itraconazole $\mathrm{e}^{(16)}$ in systemic mycosis have been described, however they has not been used to assess compliance in the routine clinical setting, in contrast to other diseases, such as epilepsy. We believe that assessing antifungal therapeutic levels is a feasible strategy, and could be useful in controlling PCM treatment.

In our study, the highest loss to follow-up rate occurred in the first 4 months of treatment. Compliance to prolonged treatments for chronic infectious diseases is a clinical challenge. Patients with tuberculosis also present high rates of discontinuation of treatment, despite presenting different demographic and epidemiological profile of patients with PCM. A study on tuberculosis showed a similar time frame for the discontinuation of the treatment, the median time of which was 4.0 (range 0.5 to 28.9) months. ${ }^{(17)}$ A low perception of disease severity may be a risk factor for treatment abandonment. ${ }^{(18)}$ In patients with PCM, clinical improvement or clinical cure (characterized respectively by a decrease or disappearance of the symptomatology, such as dyspnea and skin/mucous membrane lesions) gives the patient the impression of being "cured". (7) This time period is critical, during which treatment compliance should be the focus; this should be emphasized during the follow-up appointments.

In our study, demographic and epidemiologic variables, such as sex, age range, residence, and rural work activities, were not associated with compliance to a therapeutic regimen, which is in line with previous reports. ${ }^{(10)}$ The geographic location of the patients, i.e. metropolitan or rural areas, may have an effect on accessibility to medical care; however, it did not affect treatment compliance in our study. The World Health Organization considers illiteracy, poor economic conditions, and unemployment to be determinants of poor compliance to treatment of chronic comorbidities. ${ }^{(10,11)}$ However, in our study, no association between education level and treatment compliance was observed.

Our study also showed no association between alcohol consumption and treatment compliance. 
Table 1. Demographic, clinical, therapeutic, co-morbidities and treatment compliance among 184 patients with paracoccidioidomycosis.

\begin{tabular}{|c|c|c|c|}
\hline Variables & Compliance & Non-compliance & p-value \\
\hline Sex/male* & $80 / 82(97.6)$ & $96 / 102$ (94.1) & 0.557 \\
\hline \multicolumn{4}{|l|}{ Age rage, years ${ }^{\dagger}$} \\
\hline 00-19 & $1 / 82(1.2)$ & $3 / 102(2.9)$ & 0.390 \\
\hline $20-29$ & $1 / 82(1.2)$ & $3 / 102(2.9)$ & 0.390 \\
\hline $30-39$ & $12 / 82(14.6)$ & $15 / 102(14.7)$ & 0.425 \\
\hline $40-49$ & $26 / 82(31.7)$ & $36 / 102(35.3)$ & 0.496 \\
\hline $50-59$ & $26 / 82(31.7)$ & $25 / 102(24.5)$ & 0.179 \\
\hline$\geq 60$ & $16 / 82(19.5)$ & $20 / 102(19.6)$ & 0.433 \\
\hline Resident in Campo Grande ${ }^{\ddagger}$ & $35 / 82(42.7)$ & $38 / 101(37.6)$ & 0.487 \\
\hline Rural worker $\ddagger$ & $32 / 79(40.5)$ & $38 / 91(41.8)$ & 0.869 \\
\hline Cigarette smoker & $76 / 82$ (92.7) & 97/101 (96.0) & 0.347 \\
\hline Alcoholism ${ }^{\ddagger}$ & $73 / 81(90.1)$ & $79 / 95(83.2)$ & 0.180 \\
\hline \multicolumn{4}{|l|}{ Education $^{\dagger}$} \\
\hline Illiterate & $8 / 79(10.1)$ & $16 / 87(18.4)$ & 0.097 \\
\hline Elementary school & $57 / 79(65.8)$ & $57 / 87(65.5)$ & 0.452 \\
\hline Middle school & $13 / 79(16.5)$ & $10 / 87(11.5)$ & 0.239 \\
\hline High school/college & $6 / 79(7.6)$ & $4 / 87(4.6)$ & 0.245 \\
\hline Tuberculosis (co-infection) ${ }^{\ddagger}$ & $15 / 82(18.3)$ & $6 / 100(6.0)$ & 0.010 \\
\hline \multicolumn{4}{|l|}{ Clinical form* } \\
\hline Chronic & $79 / 82(96.3)$ & $96 / 102(94.1)$ & 0.733 \\
\hline Acute/subacute & $3 / 82(3.7)$ & 6/102 (5.9) & \\
\hline Severity ${ }^{\ddagger}$ & & & 0.389 \\
\hline Mild & $18 / 82(21.9)$ & $29 / 102(28.4)$ & \\
\hline Moderate & $54 / 82(65.9)$ & $57 / 102(55.9)$ & \\
\hline Severe & $10 / 82(12.2)$ & $16 / 102(15.7)$ & \\
\hline \multicolumn{4}{|l|}{ Organs involved ${ }^{\ddagger \S}$} \\
\hline Lungs & $72 / 79(91.1)$ & $69 / 92(75.0)$ & 0.006 \\
\hline $\begin{array}{l}\text { Oral mucous membrane } \\
\text { infection }\end{array}$ & $59 / 81(72.8)$ & $80 / 101(79.2)$ & 0.315 \\
\hline Lymph node enlargement & $29 / 63(46.0)$ & $32 / 81(39.5)$ & 0.432 \\
\hline \multicolumn{4}{|l|}{ Antifungal compound ${ }^{\ddagger}$} \\
\hline Cotrimoxazole & $72 / 83(86.7)$ & $90 / 95$ (94.7) & 0.063 \\
\hline Itraconazole & $11 / 83(13.3)$ & $5 / 95(5.3)$ & \\
\hline
\end{tabular}

Results are presented as ratios: number of cases for each variable/number of patients evaluated in each group (compliance and non-compliance). Data in parenthesis are presented as percentages. Rural workers were defined as such if they performed rural work at present, or in the past. ${ }^{*}$ Fisher's exact test; ${ }^{+}$comparison between independent

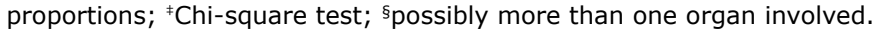

Using a different approach, another study showed that alcohol intake over $50 \mathrm{mg} /$ day had no impact on age at the onset of illness. ${ }^{(6)}$ However, in our clinical practice, wives and children of patients have reported treatment withdrawal due to alcohol abuse, which is directly related to disease development. ${ }^{(6)}$ This apparent contradiction may be due to the use of a dichotomous variable for frequent alcohol intake in this study, rather than a measurement of its amount.

An analysis of the association between compliance and the organs or systems affected by PCM revealed that pulmonary involvement, identified by radiography or CT scan, is a positive factor for compliance. These pulmonary symptoms are speculated to motivate the patients to attend follow-up appointments. Moreover, the respiratory symptoms can cause greater limitation in daily life, leading patients to be more concerned about their treatment. (19)

Compliance to therapeutic follow-up was also higher for patients with PCM-tuberculosis co-infection. The highest rate of follow-up loss occurred in the first 4 months, when patients with PCM and tuberculosis comorbidity were still on tuberculosis treatment. This finding may be related to the efforts enacted by the National Tuberculosis Control Program in Brazil, with community health workers involved in a directly observed treatment strategy. ${ }^{(20)}$ Additionally, many campaigns have emphasized the importance of never abandoning tuberculosis treatment, which could have influenced the patients' behavior in not abandoning their PCM treatment as well. 
Table 2. Variables influencing treatment compliance in 184 patients with paracoccidioidomycosis

\begin{tabular}{|c|c|c|c|c|c|}
\hline Variable & Compliance & Non-compliance & Total & $\begin{array}{c}\text { COR } \\
(95 \% \mathrm{Cl})\end{array}$ & $\begin{array}{c}\text { AOR } \\
\text { (95\% CI) }\end{array}$ \\
\hline Paracoccidioidal pulmonary lesion & & & & $3.43(1.383-8.506)$ & $2.986(1.351-6.599)$ \\
\hline Yes & 72 & 69 & 141 & & \\
\hline No & 07 & 23 & 30 & & \\
\hline All & 79 & 92 & 171 & & \\
\hline \multicolumn{6}{|l|}{ Tuberculosis co-infection } \\
\hline Yes & 15 & 06 & 21 & $3.51(1.295-9.514)$ & $2.763(1.004-7.604)$ \\
\hline No & 67 & 94 & 161 & & \\
\hline All & 82 & 100 & 182 & & \\
\hline
\end{tabular}

AOR: adjusted odds ratio; $95 \% \mathrm{CI}$ : $95 \%$ of confidence interval; COR: crude odds ratio.

The use of itraconazole could be associated with higher compliance rates due to its easier treatment regimen ( 2 pills/day for itraconazole and 4 to 6 pills/day for cotrimoxazole) and shorter treatment duration. ${ }^{(21)}$ However, our study showed no difference between medications, possibly due to the small number of patients who used itraconazole. As it was reported in the Brazilian literature, the most commonly used antifungal compound to treat PCM is cotrimoxazole..$^{(14,22)}$ Cotrimoxazole is still the most used drug to treat PCM in Brazil because it is given free of charge to the patients through the public health system.

Treatment is considered completed after at least 12 months, if itraconazole was used, or 24 months if cotrimoxazole was used, and until the patient reaches and sustains serological cure for 6 months. ${ }^{(23)}$ Therefore, immunodiffusion is very useful in the follow-up of patients, and when they do not present a significant decrease in the serological titres, it is suspected that they are not complaining to the treatment. In many patients, the serological cure criteria could not be used because serological examination was not performed or was negative at admission. About one-fifth of the patients had negative serology at admission, and this could be explained by the use of antigen obtained from $P$. brasiliensis strain B339 for serological test in our service.

The lack of standardization in antigen production for PCM serology makes the control of cure difficult in some services. The recent molecular identification of several species of fungi of the genus Paracoccidioides revealed different antigenic compositions among the species. ${ }^{(24)}$
As the serological reactions are specific, patients with PCM caused by $P$. lutzii produce antibodies that are rarely detected by reactions in which the antigen used was isolated from $P$. brasiliensis species. As the highest concentration of P. lutzii was described in the Center-West Region of Brazil, it is possible that our serological negative cases at admission were caused by $P$. lutzii. Recently, a $P$. lutzii antigen has been identified and isolated, ${ }^{(25)}$ which is not yet available for the vast majority of the clinical services. The same work of antigen identification and antigen validation for double immunodiffusion reactions should be done for all new recognized species.

It should be noted that research is being done to identify biomarkers in the serum of patients with PCM that can confirm this disease in its different stages - active untreated disease, active disease under treatment, clinical cure and serological cure, and when it is the case, PCM relapse. ${ }^{(26)}$

Some limitations of this study are the absence of objective parameters to evaluate compliance, such as follow-up of the serum levels of the antifungal compounds. More than a century after the first report by Adolfo Lutz, (27) PCM continues to be a relevant public health issue, especially regarding its treatment.

Our results showed the importance of the treatment compliance evaluation in patients with PCM, whose clinical cure is reached much before the immunological recovery. Thus, treatment compliance should be routinely performed in every appointment, including with the support of the social service, to call the patients who did not came to the appointment.

\section{REFERENCES}

. Martinez R. Epidemiology of paracoccidioidomycosis. Rev Inst Med Trop Sao Paulo. 2015;57 Suppl 19:11-20.

2. Barrozo LV, Mendes RP, Marques SA, Benard G, Silva ME, Bagagli E. Climate and acute/subacute paracoccidioidomycosis in a hyperendemic area in Brazil. Int J Epidemiol. 2009;38(6):1642-9.

3. Coutinho ZF, Silva DF, Lazera M, Petri V, Oliveira RM, Sabroza PC, et al. Paracoccidioidomycosis mortality in Brazil (1980-1995). Cad Saúde Publica. 2002;18(5):1441-54.

4. Martinez R. Paracoccidioidomycosis: the dimension of the problem of a neglected disease. Rev Soc Bras Med Trop. 2010;43(4):480.

5. Paniago AM, Aguiar JI, Aguiar ES, da Cunha RV, Pereira GR, Londero AT, et al. [Paracoccidioidomycosis: a clinical and epidemiological study of 422 cases observed in Mato Grosso do Sul]. Rev Soc Bras
Med Trop. 2003;36(4):455-9. Portuguese.

6. Santos WA, Silva BM, Passos ED, Zandonade E, Falqueto A. [Association between smoking and paracoccidioidomycosis: a case-control study in the State of Espírito Santo, Brazil]. Cad Saude Publica. 2003;19(1):245-53. Portuguese.

7. Mendes RP, Negroni R, Arechavala A. Treatment and control of cure. In: Franco M, Lacaz CS, Restrepo-Moreno A, Del Negro G, editors. Paracoccidioidomycosis. London: CRC Press; 1994. p. 221.

8. Benard G, Romano CC, Cacere CR, Juvenale M, Mendes-Giannin MJ, Duarte AJ. Imbalance of IL-2, IFN-g and IL-10 secretion in the immunosupression associated with human paracoccidioidomycosis. Cytokine. 2001;13(4):248-52.

9. Peraçoli MT, Soares AM, Mendes RP, Marques SA, Guastale H, 
Meira DA, et al. Cell-mediated immunity in patients with the chronic form of paracoccidioidomycosis. Early and late evaluation after treatment. Rev Iber Micol. 1988;69.

10. Mendes RP, Moris DV, Carvalho LC, Oliveira EF, Cavalcante R, Treatment compliance in paracoccidioidomycosis. Biomedica, 2008:28. Supplement 1:103-5.

11. Organização Mundial da Saúde (OMS). Cuidados inovadores para condições crônica: componentes estruturais de ação: relatório final [Internet]. Brasília, DF: OMS; 2003 [cited 2019 Mar 7]. Available from: https://www.who.int/chp/knowledge/publications/icccportuguese. pdf

12. Maciel MH, Canini SR, Gir E. [Patients with cutaneous-mucosal paracoccidioidomycosis attended at a tertiary hospital in the interio of São Paulo State: adherence to follow-up]. Rev Eletr Enf [Internet]. 2008 [cited 2019 Mar 7];10:374-82. Available from: https://www.fen ufg.br/revista/v10/n2/pdf/v10n2a09.pdf. Portuguese.

13. Verli FD, Marinho SA, Souza SC, Figueiredo MA, Yurgel LS. [Clinicalepidemiologic profile of paracoccidioidomycosis at the Stomatology Department of São Lucas Hospital, PontificiaUniversidadeCatólica of Rio Grande do Sul]. Rev Soc Bras Med Trop. 2005;38(3):234-7. Portuguese.

14. Gomes E, Ferreira L, Patussi EV, Wingeter MA, Marangon AV, Svidizinski TE. Clinical-laboratorial and epidemiologic profile of patients with paracoccidioidomycoses in a reference service of northwesthern Parana. Cienc Cuid Saude. 2008;7(suplem. 1):5361.

15. Padilha-Gonçalves A. [Estudo das concentrações sanguíneas das sulfonamidas no decurso do tratamento da Blastomicose brasileiral. O Hospital. 1946;29:875-81

16. Hope WW, Billaud EM, Lestner J, Denning DW. Therapeutic drug monitoring for triazoles. Current Opinion in Infectious Diseases. 2008;21(6):580-6.

17. Driver CR, Matus SP, Bayuga S, Winters Al, Munsiff SS. Factors associated with tuberculosis treatment interruption in New York City. J Public Health Manag Pract. 2005;11(4):361-8.
18. Fiol FS, Oliveira Sde J, Barberato-Filho S, Junqueira FM, Rocha MC Toledo MI. Paracoccidioidomycosis: evaluation of treatment and patient profile. Braz J Infect Dis. 2013;17(6):720-1.

19. Queiroz-Telles F, Escuissato DL. Pulmonary paracoccidioidomycosis In: Seminars in Respiratory and Critical Care Medicine. New York: Thieme; 2011. v. 32. n. 6.

20. Brasil. Ministério da Saúde. Manual Técnico para controle da tuberculose. Cadernos da atenção básica - n. 6 [Internet]. Brasília DF: Ministério da Saúde; 2002 [cited 2019 Mar 7]. Available from: http://bvsms.saude.gov.br/bvs/publicacoes/manual_tecnico_ controle_tuberculose_cab6.pdf

21. Cavalcante RS, Sylvestre TF, Levorato AD, Carvalho LR, Mendes RP. Comparison of itraconazole and cotrimoxazole in the treatment of paracoccidioidomycosis. PLoS Negl Trop Dis. 2014;8:e2793.

22. Matos WB, Dos Santos GM, Silva VE, Rosário Gonçalves EG Silva AR. Paracoccidioidomycosis in the state of Maranhão, Brazil: geographical and clinical aspects. Rev Soc Bras Med Trop. 2012;45(3):385-9

23. Mendes RP, Cavalcante RS, Marques SA, Marques ME, Venturin $J$, Sylvestre TF, et al. Paracoccidioidomycosis: Current Perspectives from Brazil. Open Microbiol J. 2017;11:224-82.

24. Turissini DA, Gomez OM, Teixeira MM, McEwen JG, Matute DR Species boundaries in the human pathogen Paracoccidioides. Fungal Genet Biol. 2017;106:9-25.

25. Gegembauer G, Araujo LM, Pereira EF, Rodrigues AM, Paniago AM, Hahn RC, et al. Serology of paracoccidioidomycosis due to Paracoccidioides lutzii. PLoS Negl Trop Dis. 2014;8(7):e2986.

26. Sylvestre TF, Franciscone Silva LR, Cavalcante Rde S, Moris DV Venturini J, Vicentini AP, et al. Prevalence and serological diagnosis of relapse in paracoccidioidomycosis patients. PLoS Negl Trop Dis. 2014;1:8(5):e2834.

27. Lutz A. [Uma mycose pseudococcidica localisada na bocca e observada no Brazil. Contribuição ao conhecimento das hyphoblastomycoses americanas]. Brazil-Médico. 1908;22(13):121-4 